\title{
COMPORTAMENTO HIGROSCÓPICO DE POLPA DE SERIGUELA ATOMIZADA UTILIZANDO DIFERENTES AGENTES CARREADORES DE SECAGEM
}

\author{
A. P. R. FERREIRA ${ }^{1}$, J. de P. da $\operatorname{COSTA}^{1}$, S. L. SOUSA $^{1}$, L. C. RIBEIRO. ${ }^{1}$, J. M. \\ C.COSTA ${ }^{1}$ \\ ${ }^{1}$ Universidade Federal do Ceará \\ E-mail para contato: anaufc2009@ hotmail.com
}

\begin{abstract}
RESUMO-Frutas tropicais como a seriguela, embora muito apreciadas por seus aspectos sensoriais, são perecíveis e requerem técnicas específicas para sua conservação e comercialização. A secagem por atomização (spray-dryer) consiste em um método eficaz para obtenção de polpas de frutas em forma de pós. Além disso, a utilização de agentes carreadores de secagem promove um melhor manuseio do produto final, conferindo maior proteção contra a adsorção de umidade, contribuindo para redução na higroscopicidade do produto. Dessa forma, este trabalho teve por objetivo a aplicação do processo de secagem por spray-dryer em polpa de seriguela com adição de diferentes agentes carreadores (goma arábica, fécula de mandioca e maltodextrina) e posterior análise para verificação do comportamento higroscópico dos pós obtidos. As características analisadas foram: umidade, higroscopicidade e grau de caking. Observou-se que a formulação de polpa de seriguela em pó tendo como agente carreador a goma arábica apresentou os menores valores de umidade $(4,84 \%)$, higroscopicidade $(8,36 \%)$ e grau de caking $(35,68 \%)$, quando comparado às demais formulações, indicando que esse produto apresenta melhor qualidadeetempo de vida útil mais prolongado.
\end{abstract}

\section{INTRODUÇÃO}

A seriguela (Spondias purpúreaL.), é uma fruta tropical muito apreciada e comercializada, tendo um crescente valor econômico no mercado. Segundo Saucedo-Veloz et al.(2004) seus frutos são altamente perecíveis durante o manejo pós-colheita, exibindo rápido amolecimento, susceptibilidade ao apodrecimento e mudanças no sabor.Dessa forma, torna-se necessário a aplicação de tecnologias com a finalidade de disponibilizar a fruta de forma que possibilite um aumento no tempo de vida útil e quepermita seu consumo em qualquer período do ano e não apenas na época de safra.

A secagem é uma operação unitária de retirada de água de um produto por evaporação ou sublimação, mediante aplicação de calor sob condições controladas, tendo como finalidade conservar alimentos através da diminuição da atividade de água (Augusta, 2011).Uma das técnicas utilizadas para obtenção de produtos em pó é a secagem em spray-dryer, onde 


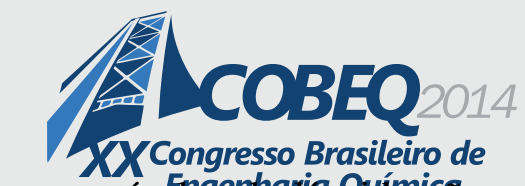

\section{9 a 22 de outubro de 2014 \\ Florianópolis/SC}

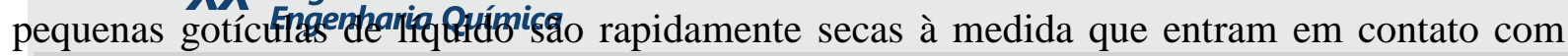
uma corrente de ar quente no interior de uma câmara de secagem (Gavaet al., 2009). A rápida evaporação da água permite manter baixa a temperatura das partículas, de maneira que a alta temperatura do ar de secagem não afete tanto as características do produto (Daiúto e Cereda, 2003).

As características do pó produzido em secadores por aspersão dependem principalmente das variáveis operacionais do secador (temperaturas de entrada e saída do ar do secador), da composição do suco ou polpa de frutas, da concentração de sólidos e também do tipo de aditivo utilizado na formulação. O uso de aditivos (ou agentes carreadores) promotores de secagem é um procedimento indispensável na secagem por aspersão da maioria das polpas de frutas, visto que esses materiais, por conter alto teor de açúcares, são propícios a caramelização, inviabilizando o processo (Shahidi e Han,1993). Além disso, a utilização de agentes carreadores pode promover um melhor manuseio do produto final obtido, conferindo uma maior proteção contra a adsorção de umidade do ambiente, tornando-o menos higroscópico (Tonon et al., 2009). Na secagem por spray dryer é comum o uso da maltodextrina com baixa dextrose equivalente, xaropes de glicose, frutose, goma arábica, pectina, lactose, proteínas, agentes antiumectantes, entre outros (Augusta, 2011).

Diante do exposto, este trabalho teve por objetivo a obtenção de polpa de seriguela atomizada utilizando diferentes agentes carreadores de secagem (goma arábica, fécula de mandioca e maltodextrina DE20) e posterior estudo do comportamento higroscópico dos pós para avaliar a qualidade e identificar a formulação que apresentou as melhores características.

\section{MATERIAIS E MÉTODOS}

\subsection{Materiais:}

Foram utilizadas polpas de seriguela congeladas, adquiridas no comércio da cidade de Fortaleza-CE e transportadas para o Laboratório de Controle de Qualidade de Alimentos e Secagem do Departamento de Tecnologia de Alimentos da Universidade Federal do Ceará DETAL/UFC, sendo armazenadas em freezer a $-18^{\circ} \mathrm{C}$ até sua utilização.

\subsection{Secagem em Spray-dryer}

Após descongelamento, elaborou-se uma polpa formulada composta de $90 \%$ de polpade seriguela e $10 \%$ do agente carreador de secagem. Os agentes carreadores utilizados nesse trabalho foram a goma arábica(F1), a fécula de mandioca(F2) e a maltodextrina (DE20) (F3). O fluxograma de obtenção dos pós encontra-se apresentado a seguir: 


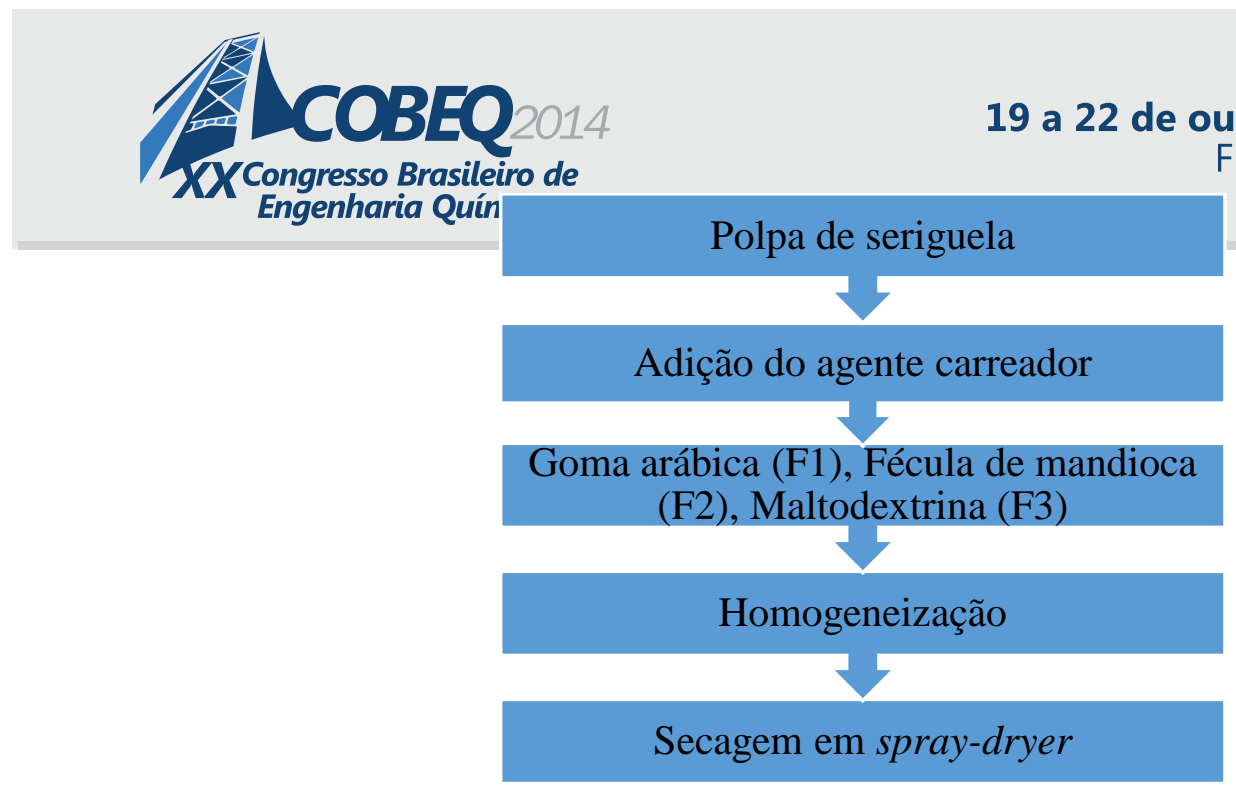

Figura 1 - Fluxograma de obtenção de seriguela atomizada.

As formulações foram submetidas ao processo de secagem em um Spray-dryer modelo MSD 1.0 da marca Labmaq do Brasil, utilizando um bico pneumático de 1,2 $\mathrm{mm}$ e, as seguintes variáveis de processo: vazão de alimentação da mistura $(0,5 \mathrm{~L} / \mathrm{h})$, vazão de ar quente $(3,5 \mathrm{~L} / \mathrm{h})$, temperatura de entrada $\left(120^{\circ} \mathrm{C}\right)$ sendo mantida constante a velocidade do ar $(30 \mathrm{~L} / \mathrm{min})$ e pressão de atomização (100 psi). Após o processo, as amostras foram armazenadas em recipientes herméticos no interior de dessecadores, até o momento da realização das análises.

\subsection{Análises:}

Foram realizadas as seguintes análises nos pós de polpa de seriguela: umidade, higroscopicidade e grau de caking. Todas as análises foram realizadas em triplicata.

A análise de umidade foi realizada em estufa a vácuo a $70^{\circ} \mathrm{C}$, sob pressão reduzida. $\mathrm{O}$ resultado foi expresso em $\%$ de umidade de acordo com a metodologia proposto pelo Instituto Adolfo Lutz (2008).

A análise de higroscopicidade foi determinada a partir da metodologia descrita por Goula e Adampoulos (2008), no qual consiste em espalhar aproximadamente 1 grama de pó de maneira uniforme sobre uma placa de petri (triplicata) e manter a amostra em uma célula com umidade relativa de ar (UR) de $75 \%$ durante período de 90 minutos, sendo verificado posteriormente o ganho de umidade do pó. Os pós obtidos foram classificados de acordo com GEA Niro Research Laboratory (2003), conformetabelaa seguir. 
Engenharịłaqúmirgãões de higroscopicidade dos pós.

\begin{tabular}{cc}
\hline Higroscopicidade & Porcentagem (\%) \\
\hline Não higroscópico & $<10 \%$ \\
Ligeiramente higroscópico & $10,1-15 \%$ \\
Higroscópico & $20,1-25 \%$ \\
Muito higroscópico & $15,1-20 \%$ \\
Extremamente higroscópico & $>25 \%$ \\
\hline
\end{tabular}

Fonte: GEA Niro Research Laboratory 2003.

Após a determinação da análise anterior as placas contendo as amostras foram levadas a estufa a $102^{\circ} \mathrm{C}$ por período de uma hora, sendo em seguida colocadas em dessecadores para resfriamento. Posteriormente, o pó foi desprendido da placa de petri e transferido para uma peneira com malha de $500 \mu \mathrm{m}$, sendo submetido à agitação em um agitador de peneiras para análise granulométrica, marca Bertel LTDA, por cinco minutos. O pó retido na peneira foi expresso como grau de caking (JAS e DAS, 2004). A classificação quanto ao caking do pó foi realizada conforme Gea Niro Research Laboratory (2003) seguindo a tabela 2.

Tabela 2 - Padrões de grau de caking dos pós.

\begin{tabular}{cc}
\hline Grau de caking & Porcentagem (\%) \\
\hline Não há formação de caking & $<10 \%$ \\
Ligeira formação de caking & $10,1-20 \%$ \\
Pó com formação de caking & $20,1-50 \%$ \\
Pó com muita formação de caking & $>50 \%$ \\
Pó com extrema formação de caking & $100 \%$ \\
\hline
\end{tabular}

Fonte: GEA Niro Research Laboratory 2003.

\subsection{RESULTADOS E DISCUSSÃO}

Os resultados da avaliação do comportamento higroscópico do pó de seriguela (com adição de diferentes agentes carreadores) no que concernem aos parâmetros de umidade, higroscopicidade e grau de caking estão apresentados na Tabela 3. As siglas F1, F2 e F3 


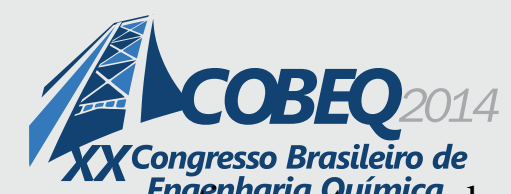

19 a 22 de outubro de 2014

Florianópolis/SC

referem-se, respegervaffierReúmiç̧olpa de seriguela em pó contento goma arábica, fécula de mandioca e maltodextrina como agente carreador durante o processo de secagem.

Tabela 3 -Caracterização higroscópica dos pós alimentícios de seriguela.

\begin{tabular}{cccc}
\hline Formulação & Umidade (\%) & $\begin{array}{c}\text { Higroscopicidade } \\
(\%)\end{array}$ & $\begin{array}{c}\text { Grau de caking } \\
(\%)\end{array}$ \\
\hline F1 & 4,84 & 8,36 & 35,68 \\
F2 & 5,35 & 9,21 & 74,81 \\
F3 & 8,30 & 9,50 & 75,82 \\
\hline
\end{tabular}

A partir dos resultados referentes à umidade observa-se que o pó contendo goma arábica apresentou menor valor, no entanto, todos os produtos estão de acordo com o estabelecido pela legislação brasileira para produtos de frutas secos ou desidratados, que preconiza um valor máximo de $25 \%$ de umidade (Brasil,2005).

A higroscopicidade é uma característica muito marcante nos alimentos em pó, sendo influenciada pelo conteúdo de umidade do próprio produto (Pereira, 2000). No caso de pós de frutas, os açúcares (sacarose, glicose e frutose) são responsáveis por fortes interações com a molécula de água por causa dos terminais polares presentes nessas moléculas (Jayas e Das, 2004).

Observa-se que os carreadores utilizados tiveram influência sobre os valores de higroscopicidade dos pós obtidos. É possível afirmar que, de acordo com Gea Niro (2003), as três formulações podem ser classificadas como pós não higroscópicos por apresentarem valores inferiores a 10\%, sendo que a formulação contendo goma arábica (F1) obteve menor percentual. De acordo comOliveira(2008), a goma arábica por apresentar maiores valores de transição vítrea $(\mathrm{Tg})$ quando comparada à maltodextrina, torna-se mais efetiva na redução da higroscopicidade dos pós. A formulação contendo maltodextrina de dextrose equivalente (DE) 20 apresentou maior ganho de água durante a exposição do produto à umidade relativa de $75 \%$. Esse comportamento pode estar relacionado com o maior número de ramificações com grupos hidrofílicos apresentado pela maltodextrina $20 \mathrm{DE}$, podendo absorver facilmente a umidade do ar ambiente. O conteúdo de umidade é um dos fatores que mais afetam a estabilidade do pó, uma vez que pequena quantidade de água é suficiente para depreciar a temperatura de transição vítrea (Tg) e, por conseguinte, aumentara mobilidade da matriz durante a estocagem (Bhandari e Hartel, 2005).

Tonon et al.(2009) ao realizarem pesquisa com suco de açaí em pó obtiveram valor de higroscopicidade de $17,56 \%$ no produto contendo $10 \%$ de maltodextrina, no entanto, os mesmos observaram que nos produtos com concentrações de 20 e $30 \%$ de maltodextrina os valores foram menores, o que permitiu a afirmação de que o aumento na concentração de maltodextrina resultou em pós menos higroscópicos. Rodríguez-Hernández et al. (2005), trabalhando com secagem de figo-da-Índia em spray dryer, utilizando concentrações de maltodextrina de 18 a 23\%, verificaram que o tipo de maltodextrina não influenciou estatisticamente na higroscopicidade dos pós, mas observaram que os pós menos 


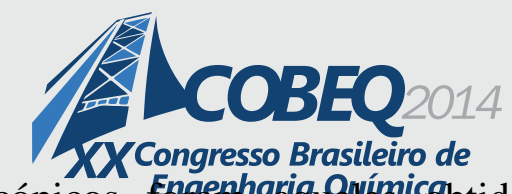

\section{9 a 22 de outubro de 2014 \\ Florianópolis/SC}

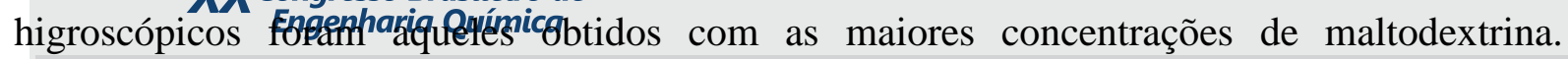
Oliveira (2012) em pesquisa com polpa de cajá liofilizada com 17\% de maltodextrina obteve resultado $8,51 \%$, caracterizando o pó como não higroscópico.

Para análise do grau de cakingde acordo com a classificação estabelecida por GEA Niro (2003), a formulação 1(F1) por apresentar valor inferior a 50\% é considerada como pó caking, esse valor encontra-se de acordo com o desejado para alimentos em pó que situa-se entre 5e 34\%,de acordo com Jayas e Das(2004). As demais formulações F2 e F3 com percentual acima de $50 \%$ e abaixo de $100 \%$ são consideradas como pó muito caking, ou seja, são pós em que ocorre a formação de aglomerados, dificultando a reconstituição e afetando a qualidade do produto.Em relação à maltodextrina esse fato pode ser explicado devido ao seu baixo peso molecular e a presença de cadeias curtas com maior proporção de grupos hidrofílicos, favorecendo a absorção de água e aglomeração dos constituintes do pó. Sierra et al.(2007) trabalhando com polpa de manga atomizada obteve $86 \%$ de aglomeração quando utilizou $25 \%$ de maltodextrina, valor acima dos encontrados neste trabalho, o que deve estar associado as diferenças relacionadas às frutas pesquisadas e às concentrações dos agentes carreadores utilizados durante os processos de secagem.

\section{CONCLUSÃO}

A partir dos resultados obtidos, observou-se que a formulação de polpa de seriguela em pó tendo como agente carreador de secagem a goma arábica apresentou os menores valores de umidade, higroscopicidade e grau de caking, quando comparado às demais formulações, indicando que esse produto tem melhor qualidade e tempo de vida útil mais prolongado.

\section{REFERÊNCIAS}

AUGUSTA, I.M. Extração e secagem da casca de jambo vermelho (Syzygium malaccensis, (L) Merryl et Perry) para obtenção de corante.2011. Tese (Doutorado) - Programa de Pós- Graduação de Processos, Universidade Federal do Rio de Janeiro, Rio de Janeiro, 2011.

BHANDARI, B. R.; HARTEL, R. W. Phase transitions during food powder production and powder stability. In: ONWULTAT, C. (Ed.). Encapsulated andpowdered foods. Boca Raton: Taylor \& Francis, 2005. p. 261-292.

BRASIL. Agência Nacional de Vigilância Sanitária - ANVISA. Resolução RDC no 272 de 22 de setembro de 2005. Regulamento Técnico para Produtos Vegetais, Produtos de Frutas e Cogumelos Comestíveis, revogando a resolução - CNNPA n ${ }^{\circ} 12$, de 24 de julho de 1978. Diário Oficial da União, Brasília 23 de setembro de 2005. 
DAIÚTO, E. R.; CEREDA, M. P. Amido como suporte na desidratação por atomização e em microencapsulamento. In: Cereda, M. P.; Vilpoux, O. F. Tecnologias, usos epotencialidades de tuberosas amiláceasLatino Americanas. São Paulo: Fundação Cargill, 2003.

GAVA, A.J; SILVA, C.A.B. DA; FRIAS, J.R.G. Tecnologia de Alimentos: princípios e aplicações.Edição revisada e atualizada. São Paulo: Nobel, 2009.

GEA Niro Research Laboratory.Analyticalmethods dry milk products. GEA Niro analytical methods. Soeborg, Denmark, 2003.

GOULA, A. M.; ADAMOPOULOS, K. G. A new technique for spray drying orange juice concentrate.Innovative Food Science and Emerging Technologies,v. 11, p.342 - 351, 2010 .

INSTITUTO ADOLFO LUTZ. Normas Analíticas, métodos químicos e físicos para análise de alimentos. $3^{\mathrm{a}}$ ed. São Paulo: Instituto Adolfo Lutz. 1, 2008.

JAYAS, S.; DAS, H.Effect of matodextrin, glycerol monostearate and tricalcium phosphate on vaccum dried mango powders properties.J. of Food Engineering, v.63, p.125-134, 2004.

OLIVEIRA,M.A. Avaliação da influência de adjuvantes de secagem sobre as propriedades de suco de caju atomizado. Dissertação (mestrado)- Pós-Graduação em Tecnologia de Alimentos, Universidade Federal do Ceará, Fortaleza,2008.

OLIVEIRA, G.S. Aplicação do processo de liofilização na obtenção de cajá em pó:avaliação das características físicas, físico-químicas e higroscópicas. Dissertação (Mestrado) Departamento de Tecnologia de Alimentos, Universidade Federal do Ceará, FortalezaCE,2012.

RODRÍGUEZ-HERNANDEZ, G. R. ; GONZÁLEZ-GARCÍA, R.; GRAJALES-LAGUNES, A.; RUIZ-CABRERA, M. A.; ABUD-ACHILA, M. Spray-drying of cactus pear juice (Opuntiastreptacantha): Effect on the physicochemical properties of powder and reconstituted product. Drying Technology, v. 23, p. 955-973, 2005. 
SAUCEDO-VELOZ, C.; PÉREZ-LÓPEZ, A.; ARÉVALO-GALARZA, M.L.; MURATALLA-LÚA, A. Effect of the maturity stage on postharvest quality and shelf life in Mexican plum (Spondias purpurea L.) fruits. Rev.Fitotecnia Mexicana, Chapingo, v.27, p.133-139, 2004.

SHAHIDI, F.; HAN, X.Q. Encapsulation of food ingredients. Critical Reviews in FoodScience and Nutrition, Boca Raton, v. 33, p.501-547, 1993.

SIERRA, D. M.; ROSA, N. N.; GABAS, A. L. Influência da adição de maltodextrina na atomização de polpa de manga em spray dryer. Simpósio Internacional de Iniciação Científica da USP, 2007

TONON, R. V.; BRABET, C.; HUBINGER, M. D. Influência da temperatura do ar de secagem e da concentração de agente carreador sobre as propriedades físico-químicas do suco de açaí em pó. Rev.Ciência e Tecn.Alimentos, v. 29, p. 444-50, 2009. 